renal failure requiring short-term dialysis post transplantation. Long-term complications included biliary anastomotic stricture in 6 (31\%) patients and vascular complications in 3 (2 hepatic artery thrombus, 1 hepatic vein stenting). One patient acquired hepatitis B from the transplanted liver. Reasons for re-transplantation were hepatic artery thrombosis (2), recurrent cirrhosis with portal hypertension (1) and primary non-function of the graft (1). Seven (35\%) transplants had cirrhosis confirmed on biopsy (5) or clinically (ascites (1) or oesophageal varices (1)) at a mean time of 25.6 months post transplant (range 12-48 months). Five-year mortality in the cohort was $25 \%$.

Conclusion Hepatitis C accounted for $<10 \%$ of OLT episodes in Northern Ireland during the study period. This demand may increase in the future as the chronic complications of previously undiagnosed hepatitis $\mathrm{C}$ are seen. One third of this small cohort developed cirrhosis within a few years of OLT.

Competing interests None declared.

\section{PM0-161 HEPATITIS E (HEV) IN SOUTH WEST ENGLAND. GEOGRAPHICAL, ENVIRONMENTAL AND SOCIAL FACTORS: A CASE CONTROL STUDY}

doi:10.1136/gutjnl-2012-302514b.161

\begin{abstract}
1,2 J Hunter, ${ }^{* 1} \mathrm{R}$ Madden, ${ }^{1} \mathrm{~A}$ Stone, ${ }^{1} \mathrm{~N}$ Osborne, ${ }^{1} \mathrm{~B}$ Wheeler, ${ }^{3} \mathrm{M}$ Barlow, ${ }^{1} \mathrm{R}$ Bendall, ${ }^{4} \mathrm{~N}$ Lin, ${ }^{4} \mathrm{~W}$ Henley, ${ }^{1} \mathrm{~W}$ Gaze, ${ }^{1} \mathrm{H}$ Dalton. ${ }^{1}$ European Centre for Environment \& Human Health, Peninsula College of Medicine and Dentistry; ${ }^{2}$ Universities of Exeter and Plymouth, Truro; ${ }^{3}$ Health Protection Agency, St Austell; ${ }^{4}$ Centre for Health and Environmental Statistics, University of Plymouth, Plymouth, UK
\end{abstract}

Introduction $\mathrm{HEV}$ is an emerging infection in developed countries, and is considered a porcine zoonosis. HEV has been found in pigs world wide and a number of water courses. In most cases the route of infection remains uncertain. A previous UK study showed that HEV was associated geographically to pig farms and coastal areas. ${ }^{1}$ AIM: To study the geographical, environmental and social factors in HEV infection.

Methods Cases of HEV and controls were identified from 2147 consecutive patients attending the Jaundice Hotline clinic, Cornwall (1999-2011). For each case and control the following were recorded: home postcode, distance from home to nearest pig farm, distance from home to coast, rainfall levels during the 8 weeks prior to presentation and socioeconomic status. A further 611 Cornish residents were tested for anti-HEV IgG to determine geographic differences in HEV seroprevalence.

Results 40 cases of HEV were identified. Seven were excluded from study as they contracted HEV outside Cornwall. 132 age/sex match controls were identified. 20/33 HEV cases clustered in the west of Cornwall, indicating that the geographical distribution was not uniform $(\mathrm{OR}=2.7,95 \% \mathrm{CI} 1.1$ to $6.5, \mathrm{p}=0.023)$. The seroprevalence of anti-HEV IgG in 611 Cornish residents increased gradually with age, and after adjusting for age/sex, there was no difference in seroprevalence between west Cornwall and the remaining study area. There was no difference between cases and controls in distance from the nearest pig farm, socioeconomic status or rainfall during the 8 weeks preceding disease presentation. Cases were more likely to live within $2000 \mathrm{~m}$ from the coast $(\mathrm{OR}=2.78,95 \%$ CI 1.20 to 6.67, $\mathrm{p}=0.02$ ), and this association remained significant after adjusting for age, sex, urban/rural domicile, proximity to pig farms and socioeconomic status.

Conclusion Cases of HEV are not uniformly distributed in Cornwall and cluster in the west of the county. This is not due to increased exposure to HEV at population level as there was no difference in HEV seroprevalence in the west of Cornwall and the rest of the study area. Proximity to a pig farm does not appear to be a risk factor for contracting HEV. Living within $2000 \mathrm{~m}$ of the coast does appear to be a risk factor, but the reason for this is uncertain.

Competing interests None declared.

\section{REFERENCE}

1. Ijaz $\mathbf{S}$ et al. J Infect Dis 2005;192:166-72.

\section{PMO-162 PREGNANT MOTHERS WITH CHRONIC HEPATITIS B (HBV): HOW OFTEN IS TREATMENT NEEDED?}

doi:10.1136/gutjnl-2012-302514b.162

${ }^{1} \mathrm{~J}$ Dyson, ${ }^{*}{ }^{2} \mathrm{E}$ Michael, ${ }^{2} \mathrm{~A}$ Turley, ${ }^{3} \mathrm{~S}$ Moses, ${ }^{3} \mathrm{M}$ Valappil, ${ }^{4,5} \mathrm{M}$ Hudson, ${ }^{4,5} \mathrm{M}$ Bassendine, ${ }^{4,5} \mathrm{~S}$ McPherson. ${ }^{1}$ Northern Deanery, Newcastle University, Newcastle, UK; ${ }^{2}$ Obstetrics, Newcastle upon Tyne NHS Trust, Newcastle University, Newcastle, UK; ${ }^{3} H P A$, Newcastle University, Newcastle, UK; ${ }^{4}$ Liver Unit, Freeman Hospital, Newcastle University, Newcastle, UK; ${ }^{5}$ Institute of Cellular Medicine, Newcastle University, Newcastle, UK

Introduction HBV is a common cause of chronic liver disease worldwide. Vertical transmission is the commonest mode of infection. Since 2000 antenatal HBV screening is offered to all pregnant women in the UK. The British Viral Hepatitis Group recommend treating mothers with an HBV DNA level of $>10^{7} \mathrm{IU} / \mathrm{ml}$ with antivirals in the 3rd trimester to reduce the transmission risk. Few studies have evaluated the epidemiology/management of pregnant patients with $\mathrm{HBV}$ in the UK. We reviewed the management of mothers with HBV attending our obstetric services.

Methods Retrospective notes review of all HBV positive mothers who attended the obstetric service from January 07 to November 11. Data were collected on patient demographics, viral serology, HBV DNA and ALT levels and HBV management during their first pregnancy in the time period.

Results $81 \mathrm{HBsAg}$ positive mothers (median age 28, 18-44) had 113 pregnancies in the study period. $96 \%$ were referred to the viral hepatitis service; however $28 \%$ of women did not attend $>1$ appointment. The mothers were born in 28 countries, most commonly China (30\%) followed by countries in Eastern Europe (17\%), Africa (16\%), South Asia (16\%) and elsewhere (21\%). $29 \%$ were known to have chronic HBV (cHBV). All mothers were tested for $\mathrm{HBeAg} / \mathrm{Ab}$ status: $15 \%$ were $\mathrm{HBeAg}$ positive, $85 \% \mathrm{HBeAg}$ negative and $79 \%$ anti-HBe positive. $85 \%$ had HBV DNA checked during the pregnancy. $9 \%$ had active $\mathrm{HBeAg}$ positive cHBV (HBV DNA > $20000 \mathrm{IU} / \mathrm{ml}$, ALT >40), 3\% had active HBeAg negative cHBV (HBV DNA > 2000 and ALT >40), 9\% were immunotolerant (HBeAg positive, ALT <40), 60\% were inactive carriers (HBV DNA $<2000$ and ALT $<40$ ) and $19 \%$ were indeterminate. $13 \%$ of mothers had a HBV DNA $>10^{7} \mathrm{IU} / \mathrm{ml}$, but only two patients were treated with tenofovir in the 3rd trimester. Of the eight patients with active HBV, six were successfully treated post-partum with oral antivirals/PEG-Interferon and two became inactive. $20 \%$ of inactive carriers experienced a post-partum flare in ALT that settled spontaneously.

Conclusion A high proportion of $\mathrm{HBV}$ infected mothers were born overseas; $>1$ in 6 had active cHBV or HBV DNA $>10^{7} \mathrm{IU} / \mathrm{ml}$ and were eligible for treatment to reduce the vertical transmission risk and/or prevent disease progression. All HBV infected mothers should be assessed for treatment and efforts to improve attendance at clinic appointments need to be intensified.

Competing interests None declared. 